\title{
Comunicação

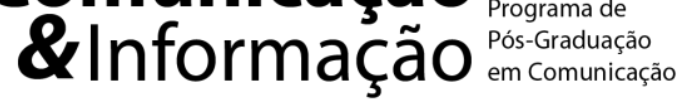

\section{O Uso do Corretor Automático Vinculado ao Aplicativo Whatsapp na Escrita de Jovens Estudantes}

\author{
The Use of the Autocorrect in Whatsapp in the Writing of Young Students
}

\author{
El Uso del Corrector Automático Vinculado a la Aplicácion Whatsapp en la \\ Redáccion de Jóvenes Estudiantes
}

Vanina Sigrist
Eliude Felizindo $^{2}$

\begin{abstract}
Resumo:
O tema da comunicação pelas redes sociais é analisado neste estudo sob a ótica da correção gramatical automática do Português Brasileiro (PB) pelo aplicativo WhatsApp. O objetivo é verificar se os recursos de correção e substituição automática disponíveis no aplicativo interferem no domínio da norma culta de jovens estudantes dos Ensinos Médio e Superior. A pesquisa é de natureza aplicada, com abordagem exploratória e qualitativa, envolvendo pesquisa de campo junto a usuários do WhatsApp contextualizados em instituições de ensino estaduais localizadas em Santos (SP). As etapas da pesquisa são: realização de um Teste de Correção Gramatical (TCG) composto por 50 sentenças redigidas em PB; preenchimento de um formulário eletrônico estruturado na escala Likert; e participação em um tópico conversacional semi-induzido sem mediação de rede social (para o grupo de controle) e com mediação (para o grupo experimental). Pode-se concluir, após tal levantamento e tratamento de dados, que a maioria dos participantes apresenta desvios generalizados da norma culta em sua escrita, impróprios à fase de escolarização em que se encontram; que há uma clara cisão entre eles, uma vez que demonstram opiniões contrárias quanto à necessidade do uso e à influência do corretor automático como facilitador do emprego da norma culta; e certa diminuição da ocorrência de três tipos de desvios quando o recurso da autocorreção estava acionado, concomitante ao aumento da ocorrência dos outros quatro tipos.
\end{abstract}

Palavras-chave: Corretor Automático. Aplicativo. Norma Culta em Português Brasileiro.

\begin{abstract}
:
The theme of communication through social networks is analyzed in this study from the perspective of autocorrect of Brazilian Portuguese (BP) by WhatsApp application. The objective is to verify if the autocorrect and autocomplete options available in the application interfere in mastering the standard variety of portuguese by young students from Secondary and Tertiary Education. The research has an applied nature, with an exploratory and qualitative approach, involving field research with WhatsApp users contextualized in public educational institutions located in Santos (SP). The research steps are: conducting a Grammaticality Correction Test (GCT) composed of 50 sentences written in BP; filling in an electronic form structured on the Likert scale; and participation in a semi-induced conversational topic without social mediation (for the control group) and with mediation (for the experimental group). It can be concluded, after such survey and treatment of data, that the majority of the participants
\end{abstract}

1 Faculdades de Tecnologia do Estado de São Paulo (FATEC), Baixada Santista, SP, Brasil, vanina.sigrist01@fatec.sp.gov.br

2 Faculdades de Tecnologia do Estado de São Paulo (FATEC), Baixada Santista, SP, Brasil, eliudefelizindo@gmail.com 
present generalized deviations from the standard variety in their writing, inappropriate to the phase of schooling in which they are; that there is a clear split among them, as they demonstrate contrary opinions about the need for use and the influence of the autocorrect as a facilitator in the use of the standard language; and a certain decrease in the occurrence of the same deviations when the autocorrect option was activated.

Keywords: AutoCorrect. App. Standard variety in Brazilian Portuguese.

\section{Resumen:}

El tema de la comunicación a través de las redes sociales se analiza en este estudio desde la perspectiva de la corrección gramatical automática del portugués brasileño (PB) por la aplicación WhatsApp. El objetivo es verificar si los recursos de corrección y sustitución automáticos disponibles en la aplicación interfieren en el dominio de la norma culta de los jóvenes estudiantes de Educación Média y Superior. La investigación es de naturaleza aplicada, con un enfoque exploratorio y cualitativo, que involucra investigación de campo con usuarios de WhatsApp contextualizados en instituciones educativas estatales ubicadas en Santos (SP). Los pasos de la investigación son: realizar una prueba de corrección gramatical (TCG) compuesta por 50 oraciones escritas en PB; completar un formulario electrónico estructurado en la escala Likert; y participación en un tema de conversación semiinducido sin mediación social (para el grupo de control) y con mediación (para el grupo experimental). Se puede concluir, después de tal encuesta y tratamiento de datos, que la mayoría de los participantes presentan desviaciones generalizadas de la norma educada en su escritura, inapropiada para la fase de escolarización en la que se encuentran; que existe una clara división entre ellos, ya que demuestran opiniones contrarias en cuanto a la necesidad de uso y la influencia del agente automático como facilitador en el uso de la norma cultivada; y una cierta disminución en la ocurrencia de tres tipos de desviaciones cuando se activó la función de autocorrección, concomitante con el aumento en la ocurrencia de los otros cuatro tipos.

Palabras clave: Corrector Automático. Aplicácion. Norma culta en Portugués Brasileño.

\section{INTRODUÇÃO}

Atualmente, passados vários anos do fortalecimento da cibercultura e do predomínio dos meios digitais de comunicação, incluindo redes sociais para diversos fins, sabe-se da importância da troca de mensagens claras e inequívocas nos ambientes educacionais e empresariais. Aplicativos de transmissão instantânea de mensagens são muito utilizados para que seus usuários possam dialogar sobre projetos em comum e viabilizar tarefas. Tais aplicativos têm sido estudados também na perspectiva do ensino e da aprendizagem de diversos conhecimentos, como mediadores fundamentais da conectividade $\mathrm{e}$ do compartilhamento de saberes, dada a dimensão que ocupam no cotidiano das pessoas.

Diversos autores decidem abordar as redes digitais realçando seu caráter estruturante nas relações sociais, sua "gramática" própria que molda comportamentos humanos, sua natureza viciosa e manipuladora (MCLUHAN, 1964³ ; SERRES, 1994; ECO, 2015; LANIER, 2018). Nesse sentido, entusiasmam-se pouco pelas potencialidades que as tecnologias mais recentes oferecem, porque lhes chama a atenção o quanto facilitam a criação de grupos de

\footnotetext{
3 num contexto avant-la-lettre.
} 
indivíduos que pensam de maneira induzida sem perceberem que o controle sobre eles, sem precedentes na história da comunicação, é tanto mais sutil quanto perverso.

Nesta pesquisa, porém, o tema da comunicação pelas redes sociais será analisado no que tange à correção gramatical automática do Português Brasileiro (PB) realizada no aplicativo WhatsApp. Assim, o objetivo é averiguar a adequação à norma culta da escrita de adolescentes e jovens concluintes do Ensino Médio e ingressantes no Ensino Superior e o uso que fazem dos recursos de correção e substituição automática de vocábulos, a fim de observar se há interferência entre eles. Lança-se aqui a suposição de que tal ferramenta, ao facilitar a grafia, a acentuação, a concordância e outros aspectos tidos como padrão, pode ser considerada pelos participantes como influenciadora da qualidade da conversação que estabelecem, porque incide diretamente na adequação escrita e na imagem que os interlocutores, através do aplicativo, conseguem manter uns perante os outros.

A redação errônea dos vocábulos e sintagmas pode ocorrer por diversos motivos, como velocidade de digitação, falta de atenção ou desconhecimento das normas gramaticais. O corretor cumpre justamente a função de sinalizar, de grifar ou mesmo de automaticamente corrigir o erro, num papel educativo. A facilitação da redação, muitas vezes vista negativamente como indutora de preguiça e desinteresse pela aprendizagem deliberada, não precisa necessariamente ser vista assim: ela pode esclarecer dúvidas, ajudar em escolhas lexicais, acelerar a familiarização ortográfica. Essa é a problemática da pesquisa.

Assim, tendo em vista a possível correlação entre algoritmo e aprendizagem linguística, pretende-se discutir se o uso do corretor automático potencializa habilidades escritas em PB, melhorando os resultados interacionais.

A pesquisa é de natureza aplicada, com abordagem exploratória e qualitativa, envolvendo pesquisa de campo junto a usuários do WhatsApp contextualizados em um momento determinado de seu letramento escrito: todos jovens matriculados no último ano do Ensino Médio de uma escola estadual ou no primeiro e segundo ano do Ensino Superior de uma faculdade de tecnologia também estadual, localizadas na cidade de Santos (SP). Nesses dois espaços institucionais, já havia abertura prévia para que as pesquisadoras pudessem desenvolver o projeto, sendo que eram professoras dos participantes em potencial, o que favoreceu a execução e a confiança entre todos durante o processo. A pesquisa de campo foi parcialmente desenvolvida in loco, enquanto outras etapas, em ambiente virtual.

$\mathrm{O}$ entendimento de como ocorrem os processos digitais que viabilizam a correção de vocábulos baseia-se em conceitos do Processamento de Linguagem Natural (PLN), que busca elucidar como se desenvolve a organização da estrutura linguística utilizada pelos programas. 
O PLN consiste no desenvolvimento de modelos computacionais que realizam tarefas que dependem de informações expressas em alguma língua natural, tais como tradução e interpretação de textos, busca de informações em documentos e interface homem-máquina (PEREIRA, 2011).

O PLN proporciona que ferramentas como corretores sejam capazes de detectar irregularidades não só na ortografia, mas também na morfologia, dependendo do algoritmo utilizado, que deve ser flexionado segundo as necessidades dos usuários, fazendo com que o processador de dados compreenda aspectos técnicos da linguagem. Esse é um grande desafio, pois as línguas naturais são complexas, vivas, mutáveis, com novas expressões e modismos que transbordam do seu uso cotidiano, carregando em si ambiguidades difíceis de serem traduzidas para uma máquina.

O Brasil enfrenta problemas em várias faixas populacionais quanto à competência leitora e apropriação de uma escrita adequada à norma culta. Vitória e Christofoli (2013) esclarecem que são inúmeros os desafios porque essas carências não são superadas sequer quando da entrada e permanência no Ensino Superior, visto ser expressivo o número de alunos que revelam dificuldades ao escrever. E ainda alertam para a necessidade urgente da criação de mecanismos que favoreçam o aprimoramento dessa escrita.

Tais mecanismos podem ser criados com as tecnologias de comunicação de que se dispõe. Elas certamente oferecem recursos para fortalecer o conhecimento da norma padrão em Língua Materna (LM), bem como são, elas próprias, estruturas cognitivas e culturais importantes, que definem comportamentos, hábitos e estilos de aprendizagem humanos. Alencar (2009) enfatiza que a evolução tecnológica das últimas décadas, que barateou drasticamente os equipamentos informáticos, fez com que fosse possível visualizar diferentes linguagens, tornando-as acessíveis a qualquer pesquisador que disponha de um computador e de programas especiais desenvolvidos para o processamento da língua. Com efeito, numa disciplina de base fortemente empírica como a linguística de corpus, em que amostras representativas de um fenômeno implicam a interpretação de grandes volumes de textos, é impossível a realização de certas tarefas sem a velocidade e a acuidade no levantamento de dados proporcionadas pelo computador.

A importância do PLN está justamente na construção de um algoritmo mais acessível com o intuito de fazer seus usuários se apropriarem mais adequadamente da norma culta de sua LM.

Para Pittol e Rigo (2015, p. 33): 
$\mathrm{Na}$ área da fonética e da fonologia, encontramos muitos aplicativos de Processamento de Linguagem Natural. A fonética se ocupa com os sons e a fonologia com os fonemas e o sistema fonológico. Os desenvolvimentos observados nessas áreas estão direcionados para o reconhecimento de fala, síntese de fala e sistemas de diálogo em língua falada. Já os estudos em sintaxe e semântica são de grande importância para o desenvolvimento de programas na área de Processamento de Linguagem Natural. A sintaxe é o estudo das regras e dos constituintes das frases. A semântica é o estudo do significado das palavras e das proposições de sua utilização. Esses estudos são importantes para apoiar o desenvolvimento de sistemas que precisam compreender e/ou gerar frases. Os sistemas conhecidos como Chatterbots são um exemplo de programas que utilizam essas técnicas. Eles são programas que interagem com humanos por meio de diálogo em linguagem natural.

Os autores, assim, esclarecem como é o processo de ensinar aos sistemas as estruturas fonéticas e fonológicas, sintáticas e semânticas de uma língua natural que se quer que reproduzam e interpretem. As redes sociais têm usado potencialmente o PLN, não só em seus corretores ortográficos, mas também na transliteração de áudio em textos, como o realizado no envio de mensagens no WhatsApp que podem ser ditadas e transcritas.

\section{A ESCRITA E O CORRETOR AUTOMÁTICO NO WHATSAPP}

Alguns estudos recentes já foram elaborados com intenção de analisar as contribuições do uso do aplicativo de conversa em contexto de ensino e aprendizagem de línguas, principalmente estrangeiras (frequentemente o inglês). Bouhnik e Deshen (2014) destacam que o WhatsApp é relativamente novo, existindo pouca pesquisa sobre sua influência na comunicação interpessoal em geral, e entre professores do ensino médio e seus alunos em particular (tomando por base trabalhos como o de Church e Oliveira (2013).

Um exame do uso do WhatsApp em uma turma de uma universidade na África do Sul registrou feedback positivo dos alunos, que alegaram ser uma maneira mais fácil de se comunicar com seus professores e com o restante da turma, produzindo um discurso frutífero sobre questões relevantes em ambiente informal, onde os alunos pudessem aprender de modo íntimo, descontraído e autêntico (RAMBE; CHIPUNZA, 2013). Tal cooperação foi sentida para preencher lacunas no conhecimento e na distância física. No geral, pode-se dizer, no esteio dos estudos de Rambe e Chipunza (2013), que o WhatsApp tornou-se uma plataforma compartilhada que potencialmente aumenta a acessibilidade, incentiva a cooperação e intensifica a motivação para participar ativamente de tarefas acadêmicas.

Para Weissheimer, Caldas e Marques (2018), a experiência realizada com um grupo de alunos evidenciou que inicialmente eles cometiam vários erros de fluência que não tornaram a 
cometer na fase pós-testes, tendo tido tempo para planejar sua fala e gravar seus áudios livremente pelo WhatsApp. O observado é que os alunos que receberam feedback baseado em gramática sobre seu desempenho oral na língua inglesa como Segunda Língua (L2) demonstraram posteriormente resultados mais positivos no desenvolvimento da habilidade oral do que aqueles com feedback baseado em conteúdo. Nesse sentido, segundo os pesquisadores, suas descobertas se encaixariam nas premissas da Teoria da Notação de Schmidt (1990, apud WEISSHEIMER; CALDAS; MARQUES, 2018), que afirma que os aprendizes precisam registrar conscientemente os aspectos linguísticos de Língua Estrangeira (LE) para adquiri-los.

No entanto, entraves são reais na utilização dessa ferramenta no aprendizado, em sala de aula ou para o desenvolvimento de tarefas escolares. Singh (2018, p. 146, tradução livre) pontua alguns estudos que alertam para a importância de uma apropriação didática guiada, que evite dispersão, atrasos, perda de tempo:

O desafio que é muitas vezes esquecido é o compromisso que leva mais tempo ou, até mesmo, o desperdício de tempo. Quanto mais alguém se inscreve em SRSs [Serviços de Rede Social], mais tempo gasta. Chanania (2012) rejeita impulsivamente os sites de redes sociais como um desperdício de tempo. Madhusudhan (2012) descobriu que os alunos usam mais frequentemente as mídias sociais com uma lista maior de amigos e gastam seu tempo nas mídias dependendo disso. As pessoas usam SRS como ferramentas de procrastinação que as distraem das configurações formais de aprendizado. Deve haver orientação adequada para que os alunos utilizem seu tempo de rede social de forma mais produtiva. Por outro lado, os educadores podem usar eles próprios serviços de redes sociais, mas podem não reconhecer o potencial educacional e as oportunidades para seus alunos, ou não entender os riscos potenciais, tanto para eles quanto para seus alunos; portanto, gera um desafio maior usar SRS sem conhecimento (CHILDNET INTERNATIONAL REPORT, 2008 apud SINGH, 2018, p. 146) ${ }^{4}$.

Pesquisas que proporcionem conhecimento de como estruturar a construção do saber com redes sociais são, na perspectiva adotada aqui, indispensáveis nos dias atuais. Especificamente, é necessário verificar a possibilidade de desenvolvimento linguístico da

\footnotetext{
4 No original: Another challenge that is often overlooked is the major time commitment or even wastage of time. The more SNSs that one person signs up to, the more time is involved. Chanania (2012) impulsively dismiss social network sites as a superfluous waste of time. Madhusudhan (2012) found that students use social media more frequently with longer friends list and spend their time on social media accordingly. People use SNSs as procrastination tools that distract them from formal settings of learning. There should be proper guidance for students to utilize their social networking time more productively. On the other hand, educators may well be using social networking services themselves, but may not recognize the educational potential and opportunities for their learners, or understand the potential risks, both for themselves and their learners, therefore, it generates major challenge of using SNSs without knowledge (Childnet International Report, 2008).
} 
norma padrão do PB através dos recursos do corretor no WhatsApp, trazendo luz ao debate sobre a criação de algoritmos cada vez mais robustos, que não só favoreçam o aprendizado da norma culta (grande desafio a ser superado na educação nacional), mas, ao fazê-lo, deem melhores condições de participação social a seus usuários, fortalecendo sua identidade de grupo e sua autoconfiança comunicativa.

Em Moura (2009, apud SOUZA, QUIRINO, 2015), um levantamento de projetos desenvolvidos em vários países trouxe a conclusão de que as tecnologias móveis estavam se mostrando, à época, e ainda se mostram na atualidade, alternativas viáveis na elaboração de programas educacionais, na medida em que os computadores gerariam custos muito maiores e obrigariam ao manuseio presencial. Um bom exemplo seria a África, continente onde os dispositivos móveis são baratos e largamente disponíveis, passando a ser utilizados no ensino básico através de planos de estudo alternativos. Os relatórios citados pelos autores apontam maior alfabetização da população abrangida pelo telemóvel.

Os aparelhos celulares disponibilizam os corretores ortográficos em dois modelos principais de sistemas operacionais: Android e IOS; sendo o primeiro mais utilizado com base de operacionalização Linux, e o outro com Unix, da produtora de softwares Apple. Ambos oferecem possibilidades de ampliação do dicionário contido no banco de dados. No entanto, Android possui código aberto, o que facilita mudanças, sendo possível customizá-lo, mas, em contrapartida, falta-lhe robustez, ou seja, capacidade de rodar simultaneamente muitos processos sem ocasionar erros, o que não favorece a complementação do dicionário pelo usuário. Esse fato pode mudar em breve com os novos bancos de dados apresentados no mercado (na vertente big data, superando os sistemas tradicionais por sua capacidade de obter e tratar "grandes conjuntos de dados").

Os corretores não são exclusividade dos aparelhos móveis, sendo possível utilizá-los em computadores desktop, tablets ou na diversidade de redes sociais. Eles sugerem correções e substituições, podendo, inclusive, fazê-las autonomamente quando o recurso está acionado. No entanto, o WhatsApp fomentou a popularização dessa ferramenta, principalmente no Brasil, onde é uma das redes sociais mais usadas (junto com o Facebook, plataforma que agregou cerca de 80 milhões de usuários em 2019, segundo as estatísticas de uma projeção divulgada em Statista.com), quando proveu agilidade à correção devido ao grande volume de mensagens enviadas diariamente - o que pode, eventualmente, vir a causar situações cômicas ou mesmo constrangedoras (NUMBER, 2019).

Nas próprias mídias há centenas de exemplos corriqueiros aos quais se está sujeito quando a opção da substituição automática de palavras está ativada no dispositivo móvel: ela 
acaba por preencher o termo que começa a ser digitado e, se o usuário está desatento ou apressado, envia alguma mensagem ou postagem com erro, ora com algum uso lexical incoerente, disparatado para o contexto em questão, ora com vocábulos indesejáveis, pejorativos, com conotação sexual, entre outros. Um caso recente, ocorrido em grupo de conversa da faculdade onde foi desenvolvida esta pesquisa, mostra o usuário descontente com a sugestão do corretor:

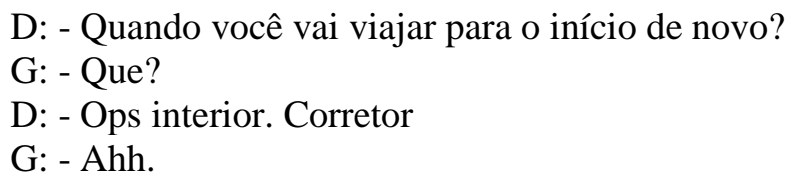

Isso se repete frequentemente quando um termo é automaticamente incorporado à redação da mensagem pela interpretação algorítmica. Por outro lado, a autocorreção permite celeridade na digitação, porque bastam duas ou três letras para que o sistema sugira o termo completo mais próximo no dicionário, acessível no teclado com um clique, evitando a digitação exaustiva de vocábulos mais longos ou acentuados, que induz, muitas vezes, ao erro. Para Manjoo (2010), o algoritmo básico de um software de correção automática é bastante simples, assim como seu design. O sistema é essencialmente o mesmo que o verificador ortográfico de um processador de texto: à medida que o usuário digita, o software verifica cada palavra em um dicionário interno e sugere alternativas quando não encontra uma correspondência; ou tenta prever o que será digitado e sugere uma palavra antes que a digitação seja concluída.

Segundo dados divulgados no site da Agência Trato (agência de propaganda e marketing digital), direcionados à área de tecnologias informacionais, 60\% dos corretores automáticos são implementados pela grande empresa de software Nuance Communications (sediada em Burlington, nos Estados Unidos), que tem em sua carteira de clientes Samsung, LG e Sony. Para identificar as palavras mais utilizadas pelos usuários de seus clientes, e para que seja possível adequá-las ao corretor, a empresa disponibiliza um programa que analisa mais de 150 dos sites mais visitados, assim como páginas muito populares e acessadas, ou especializadas em tecnologia, como Time, Sports Illustrated e CNN (SABE, 2018).

Já a Microsoft utiliza duas fontes principais para atualizar o corretor ortográfico: Twitter e Wikipedia; além de dados extras obtidos através da captação dos termos mais digitados pelas pessoas naquele momento. Uma análise do número de seguidores de alguém no Twitter ou de uma determinada palavra frequentemente usada e curtida é requisito para que entre no software da autocorreção. A maioria deles é construída para englobar em seu 
dicionário palavras digitadas rotineiramente; quando o programa corrige uma palavra e o usuário a corrige de volta, ele eventualmente não a sugere de novo, incorporando a nova grafia.

\section{A INCLUSÃo SOCIAL PELO DOMÍNIO DA NORMA CULTA}

A riqueza etno-cultural presente no Brasil confere ao povo uma diversidade não apenas de tipos, mas de formas distintas de se expressar. A língua portuguesa brasileira, nesse sentido, além de não ser uma única para todas as cidades e regiões do território nacional, difere muito da praticada em outras nações lusófonas. Tal diversidade também resulta do constante contato inter-linguístico, que favorece transformações morfológicas, sintáticas, lexicais, graduais, mas insistentes e dinâmicas, que desafiam o domínio por parte de seus falantes, nativos ou não, principalmente o das regras do padrão considerado culto, o qual exerce maior contundência nas relações socioeconômicas mais importantes à sociedade.

Lucchesi (2009, p. 31) explica que:

(...) o contato entre línguas afetou diretamente a formação dos padrões coletivos de fala da maioria da população do país (o que se denomina aqui norma popular) e só indiretamente a fala das classes economicamente privilegiadas, tradicionalmente chamada de norma culta. E os mecanismos gramaticais em que os efeitos do contato linguístico são mais notáveis são exatamente os mecanismos da concordância nominal e verbal, de modo que a falta de concordância constitui a grande fronteira sociolinguística da sociedade brasileira. É sobre ela que incide, em sua forma mais virulenta, o preconceito linguístico.

Norma culta e preconceito linguístico são fundamentalmente norteadores das relações sociais, de seus moldes, de sua significância. O indivíduo oriundo das classes mencionadas por Lucchesi (2009) como populares, que, via de regra, demonstra problemas de concordância, enfrenta consequentemente obstáculos para sua inclusão nos meios acadêmicos e empregatícios. Araújo e Dias (2014, p. 260) enfatizam essa situação, atentando para a avaliação pela qual passam os profissionais nos processos seletivos das organizações:

A relação do domínio da norma culta da língua portuguesa com a qualificação profissional nos permite constatar que, sob o ponto de vista dos selecionadores, é de grande importância que o candidato detenha tal domínio, pois, segundo eles, fazer bom uso da língua, apresentar boa expressividade oral e escrita, saber se comunicar em público e com a equipe de trabalho, é muito importante para a empresa e um diferencial valiosíssimo para o profissional que busca a inclusão e permanência, com sucesso no mercado de trabalho. 
No ciberespaço isso se repete, ou seja, muitos permanecem fadados a espaços comunicacionais completamente marginais quando não se expressam corretamente. Os meios digitais continuam a reproduzir as desigualdades de acesso, voz e participação ativa da cultura analógica, impressa, massificada, ou mesmo as agravam, de certa forma, porque ilusoriamente as camuflam quando prometem dar importância a todo e qualquer discurso. E a norma culta da língua não deixa de ser a "regra", a "lei", o fator "discriminatório-inclusivo".

Bagno (2006) esclarece que passa a ser visto como erro todo e qualquer uso que escape desse modelo idealizado; toda e qualquer opção que esteja distante da linguagem literária consagrada; toda pronúncia, todo vocabulário e toda sintaxe que revelem a origem social desprestigiada do falante, que não constem dos usos das classes urbanas letradas, com acesso à escolarização formal e à cultura legitimada - o que pode ser um complicador se estiver pleiteando aceitação em um grupo.

\section{MÉTODOS}

A amostra da pesquisa de campo aqui conduzida foi delineada, inicialmente, pela eleição de 1 (uma) turma do terceiro ano do Ensino Médio de uma escola estadual onde uma das pesquisadoras leciona há alguns anos; e de 6 (seis) turmas do primeiro ao quarto semestre do Ensino Superior tecnológico de uma faculdade estadual onde a outra pesquisadora é docente junto aos cursos de Logística, Gestão Empresarial, Sistemas para Internet e Análise e Desenvolvimento de Sistemas. O critério para a escolha dos alunos da amostra foi o enquadramento na faixa etária estabelecida: entre 14 e 24 anos de idade. Tal faixa é semelhante às aplicadas em outras pesquisas recentes conduzidas pela mesma temática (VERHEIJEN; SPOOREN，2017; UEBERWASSER; STARK，2017). Esses trabalhos enfocam prioritariamente a formação de corpora relacionados ao uso do WhatsApp na aprendizagem da norma padrão pelos jovens na Holanda e na Suíça, respectivamente. Desse modo, limita-se o grupo de controle e o grupo experimental, distinguidos unicamente pela disponibilidade de seus horários de aula, a adolescentes e jovens, excluindo-se crianças, adultos e idosos.

Os participantes foram instruídos sobre o propósito da pesquisa e convidados a participar de modo espontâneo e voluntário, estando cientes de que receberiam uma gratificação no cômputo de suas notas do bimestre corrente como retribuição por sua colaboração nas várias fases da pesquisa. Todos assinaram o Termo de Consentimento Livre e Esclarecido, com exceção daqueles de menoridade, representados por seus responsáveis, e 
guardaram consigo uma cópia. Eles não apresentavam nenhum tipo de distúrbio de aprendizagem notado ou declarado.

O período de coleta dos dados foi de Setembro a Outubro de 2019, totalizando dois meses para o cumprimento das três etapas: 1. Realização de um Teste de Correção Gramatical (TCG) composto por 50 sentenças redigidas em PB; 2. Preenchimento de um formulário eletrônico estruturado composto por doze perguntas objetivas, dentre as quais sete no padrão de escala Likert ${ }^{5}$; 3. Participação em um tópico conversacional semi-induzido a respeito de como veem a perspectiva futura da profissão escolhida por eles, sem mediação de rede social, em folhas de papel com linhas (para o grupo de controle); e participação em um chat via WhatsApp com o mesmo tópico conversacional semi-induzido (para o grupo experimental).

Houve a preocupação de que o TCG seguisse modelos já consagrados na literatura, principalmente nas áreas da linguística, da fonoaudiologia e da psicologia, em que testes desse tipo são interpretados à luz do desenvolvimento cognitivo e da aquisição de linguagem, em especial nas fases iniciais de escolarização, quando as crianças se alfabetizam (podendo elas apresentar ou não algum distúrbio de aprendizagem).

Por conseguinte, foram respeitadas as condições essenciais para aplicação de testes desse tipo sugeridas por Grégis (2007), apesar de os participantes estarem numa fase de letramento bem avançada, com a LM plenamente adquirida: 1. As sentenças eram de fácil entendimento; 2. As instruções eram claras e explicadas; 3. O número de sentenças era equilibrado (a sugestão da autora é de dez a cinquenta, com predileção por esta quantia, aqui adotada); 4. O tempo foi controlado; 5. O número de participantes era significativo (a sugestão é de sessenta ou mais, ao passo que, na amostra, atingiu-se o número de 96 indivíduos). A sexta condição foi a única não cumprida, porque trata da adequação do teste ao estudo de LE ou L2, sendo aqui o foco LM. Mesmo algumas das condições ditas recomendáveis por Grégis (2007.), voltadas a Testes de Julgamento Gramatical (TJG), e não correção, foram respeitadas, como a escolha de sujeitos não linguistas e de sentenças apropriadas ao nível escolar atendido.

As sentenças escolhidas para o teste tomaram igualmente por base outros estudos especializados, como o de Nunes e Oliveira (2000), que, ao apresentarem alguns dos resultados alcançados com o desenvolvimento do revisor gramatical ReGra, em que se empenharam pesquisadores da Universidade de São Paulo, sistematizam os erros mais

\footnotetext{
5 Usual em pesquisas de opinião em que se solicita que o participante expresse seu nível de concordância com uma afirmação através de cinco medidas: 1- Concordo plenamente; 2 - Concordo parcialmente; 3 Indiferente ou neutro; 4 - Discordo parcialmente; 5 - Discordo totalmente. Fonte: https://www.britannica.com/topic/Likert-Scale.
} 
comuns detectáveis por corretores automáticos (de editores de texto, por exemplo). Aqueles que foram representados no TCG aplicado são justamente os elencados por esses autores: 1 . Uso incorreto ou ausência de crase; 2. Uso inadequado da partícula "se"; 3. Falta de concordância verbal de particípio; 4. Falta de concordância nominal ou verbal; 5. Inadequação no uso dos verbos "fazer" e "haver"; 6. Uso incorreto de regência verbal ou nominal; 7. Vício de linguagem; 8. Equívoco no emprego de "mau" e "mal"; 9. Uso inadequado do particípio regular/irregular; 10. Pontuação inadequada.

Além dessas, observou-se a necessidade de avaliar o domínio das regras estritamente ortográficas, que, para fins de estudo dessa ordem, costumam ser contempladas em três categorias: as regularidades diretas; as regularidades contextuais ou morfológico-gramaticais, e as irregularidades.

O questionário estruturado enviado aos participantes por meio digital, na segunda etapa, seguiu o mesmo viés sociolinguístico da pesquisa como um todo, possibilitando, assim, trabalhar com quatro variáveis: sexo; idade; nível de escolaridade; condição de exposição ao aplicativo WhatsApp. Ao todo, doze questões foram apresentadas, referindo-se objetivamente às tais variáveis, e, qualitativamente, ao conhecimento, à confiança, às opções de uso e frequência dos recursos do corretor automático vinculado ao WhatsApp que cada respondente administra em seu dispositivo móvel. O questionário foi submetido aos 96 participantes, dos quais foram obtidas 69 respostas válidas e 27 respostas inválidas (enviadas fora do prazo estabelecido, incompletas ou sequer enviadas).

Subgrupos de cinco alunos foram formados para viabilizar a divisão entre grupos de controle e grupos experimentais na última etapa. Enquanto os primeiros foram selecionados a escrever sobre o tópico conversacional em ambiente não virtual, numa sessão presencial em sala de aula; os segundos interagiram por meio do chat criado no aplicativo WhatsApp. Do total de 96 participantes selecionados para a primeira etapa, com todos os TCG válidos, 18 participantes formaram o grupo total de controle nessa segunda fase, e 46 o grupo total experimental, uma vez que as atividades foram aplicadas em sala durante uma aula em que os alunos puderam ou não comparecer, ou solicitadas virtualmente sem a possibilidade de controle sobre o uso dos dispositivos móveis dos voluntários.

A duração média da atividade manuscrita foi de uma hora, sem intervalos; a duração integral da conversação virtual foi de 24 horas. Esse método encontra respaldo nos trabalhos de Riemens (2016). Ambos os grupos foram motivados pela sugestão de um tópico inicial relacionado à visão de seu futuro profissional, e podiam ler e reagir às respostas uns dos outros. O nível de interatividade, porém, foi bem maior no ambiente virtual. 


\section{RESULTADOS E DISCUSSÃO}

\subsection{ANÁLISE DOS RESULTADOS DO TESTE DE CORREÇÃO GRAMATICAL (TCG)}

O desempenho médio no TCG revelou desvios generalizados da norma culta em PB, incoerentes com o nível de educação formal contemplado na pesquisa, o qual abrange estudantes que já deveriam demonstrar domínio no uso, por exemplo, da crase, da concordância nominal e verbal, das conjugações verbais, bem como da pontuação. Como é possível verificar na Tabela 1, a média de acertos para regência verbal é muito baixa $(18,67)$, o que denota ausência de saberes estruturados quanto às diversas significações que um verbo pode assumir, assim como a concordância, aspecto que revelou um número de erros maior que o de acertos.

Tabela 1 - Erros e Acertos no TCG

\begin{tabular}{|c|c|c|c|c|c|}
\hline Tipo & Questões & Quantidade & Acertos & Erros & $\begin{array}{l}\text { Média de } \\
\text { Acertos }\end{array}$ \\
\hline Crase & $1,5,17$ & 3 & 137 & 151 & 45,67 \\
\hline Concordância & $2,4,13,14,20,27,28,32$ & 8 & 341 & 427 & 42,63 \\
\hline Ortografia & $3,8,16,22,24,36,38-43,47$ & 13 & 627 & 621 & 48,23 \\
\hline Regência & $10,12,15$ & 3 & 56 & 232 & 18,67 \\
\hline Pronomes & $21,35,45$ & 3 & 187 & 101 & 62,33 \\
\hline Pontuação & 50 & 1 & 72 & 24 & 72,00 \\
\hline Léxico & 46 & 1 & 49 & 47 & 49,00 \\
\hline Corretas & $\begin{array}{l}6,7,9,11,18,19,23,25,26,29-31 \\
33,34,37,44,48,49\end{array}$ & 18 & 1369 & 359 & 76,06 \\
\hline
\end{tabular}

Fonte: Elaborado pelas Autoras (2019)..

O número de erros em crase, concordância, regência e léxico sobrepôs o de acertos. Já em ortografia, colocação pronominal e pontuação, o número de acertos predominou. O que se pode inferir, ao observar esses dados, é que, excetuando-se as duas médias extremas, de $18,67 \%$ e $72 \%$, todas as demais se concentram entre $42 \%$ e $62 \%$, indicando um desempenho grau 5 em escala de 0 a 10 . Tais estudantes, com essa avaliação, sequer estariam inseridos na faixa de aprovação dos cursos superiores em que estão matriculados, cuja nota mínima de aprovação é 6 . O índice acentuado de desvios da norma culta era, de certa forma, esperado, 
tendo em vista o conhecimento prévio do letramento desses alunos pelas professoras pesquisadoras, mas, de todo modo, é um diagnóstico preocupante.

\subsection{ANÁLISE DOS RESULTADOS DO QUESTIONÁRIO ESTRUTURADO}

No questionário formulado e aplicado através de plataforma digital, foram contempladas as variáveis sexo, idade, nível de escolaridade e exposição ao aplicativo WhatsApp. Apurou-se que $41 \%$ eram do sexo feminino, e 59\%, masculino. Respeitando a faixa etária metodologicamente estabelecida, foram obtidos os seguintes resultados: $6 \%$ com 17 anos; $32 \%$ com 18 anos; $15 \%$ com 19 anos; $16 \%$ com 20 anos; 4\% com 21 anos; 7\% com 22 anos; 6\% com 23 anos; 13\% com 24 anos. A média de idade foi de 20 anos. Quanto ao ano escolar ou universitário, os participantes se dividiram desse modo: $13 \%$ do $3^{\circ}$ ano do Ensino Médio; $72 \%$ do $1^{\circ}$ ano; e $15 \%$ do $2^{\circ}$ ano do Ensino Superior.

O Gráfico 1 apresenta a frequência de uso do aplicativo WhatsApp pelos entrevistados, com destaque aos $76 \%$ que sinalizam para o uso o dia todo e aos somente $3 \%$ que usam menos de 3 dias na semana.

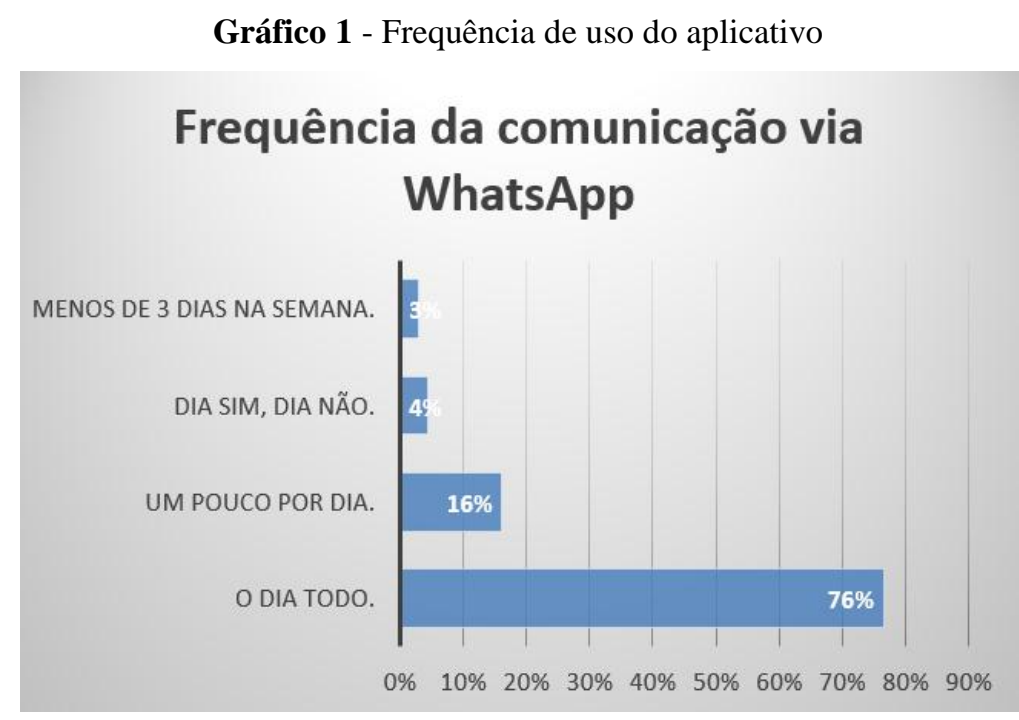

Fonte: Elaborado pelas Autoras (2019).

Quanto à participação em grupos criados no WhatsApp, os valores variaram mais. Tal questão visava investigar o comportamento dos usuários quando da participação em públicos maiores, aspecto que pode interferir no registro que se busca usar durante a comunicação escrita. 
Gráfico 2 - Grupos de conversa

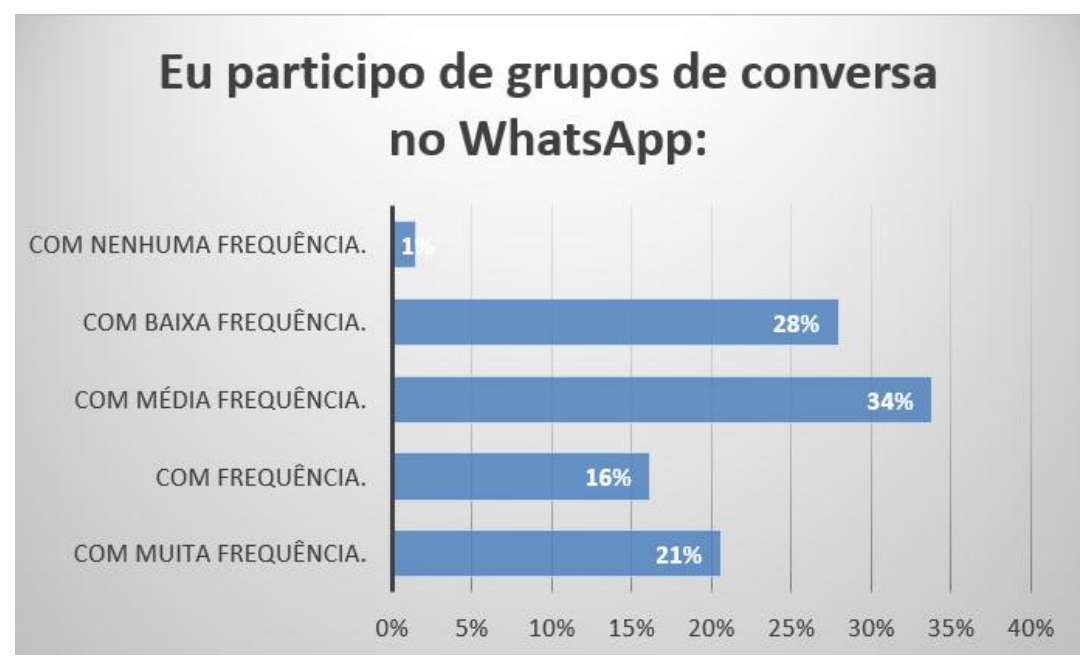

Fonte: Elaborado pelas Autoras (2019).

Vê-se que a prática de frequentação dos grupos de conversa não é generalizada, e talvez seja até, em certas situações, evitada, pelo próprio volume de mensagens que se alcança diariamente em conversas desse tipo, sempre maior quanto mais membros houver, ou pelo alto risco de dispersão do foco da comunicação.

O Gráfico 3 permite verificar que $42 \%$ dos respondentes admitem não se preocupar com a adequação de sua escrita à norma culta, mesmo estando disponível o recurso do corretor automático no aplicativo. Essa despreocupação se relaciona diretamente ao desempenho gramatical revelado no TCG. Se naquela etapa os informantes não foram capazes de identificar muitos dos acertos e corrigir os erros, nesta eles se dividem quase pela metade entre os que valorizam (58\%) demonstrar tal habilidade e os que não valorizam.

Gráfico 3 - Preocupação ao escrever

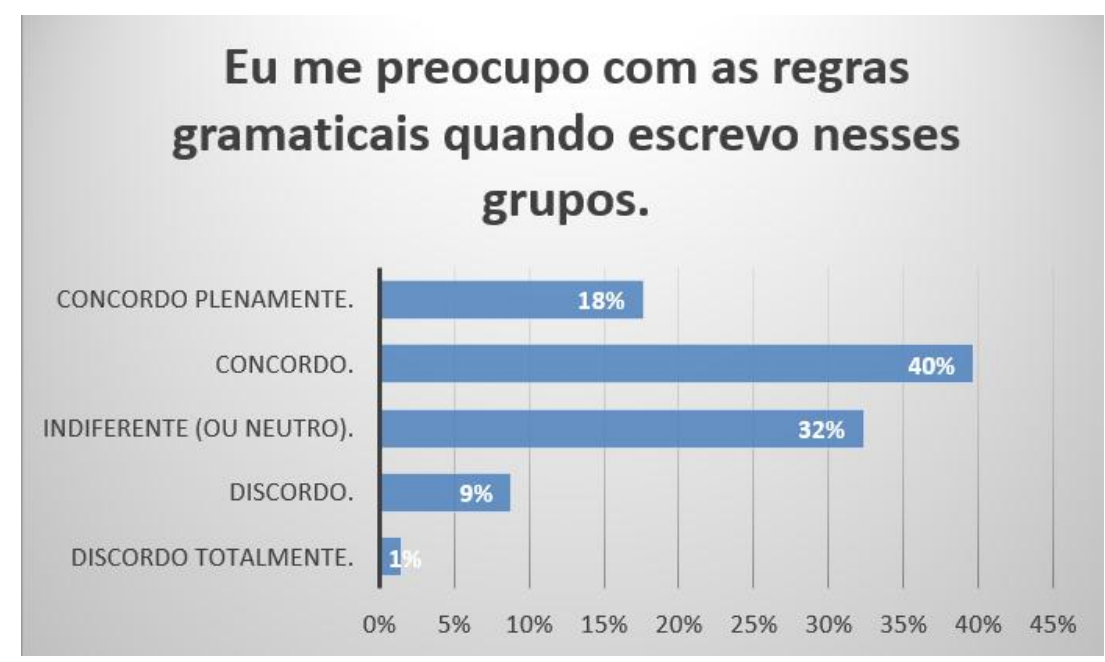

Fonte: Elaborado pelas Autoras (2019). 
Já o gráfico seguinte, complementarmente, permite visualizar que $53 \%$ dos pesquisados apresentam preocupação com a imagem que construirão de si mesmos nos grupos de conversa do aplicativo, ao passo que $20 \%$ afirmam não se importar com tal visibilidade e identidade. Essa questão amplia a perspectiva da preocupação específica com a escrita culta em público para a perspectiva do pertencimento e do possível julgamento feito com base no comportamento dentro do grupo, a fim de investigar a visão que esses jovens têm das funcionalidades do aplicativo, assim como sua consciência das implicações de usá-las.

Gráfico 4 - Preocupação com a imagem transmitida em grupos

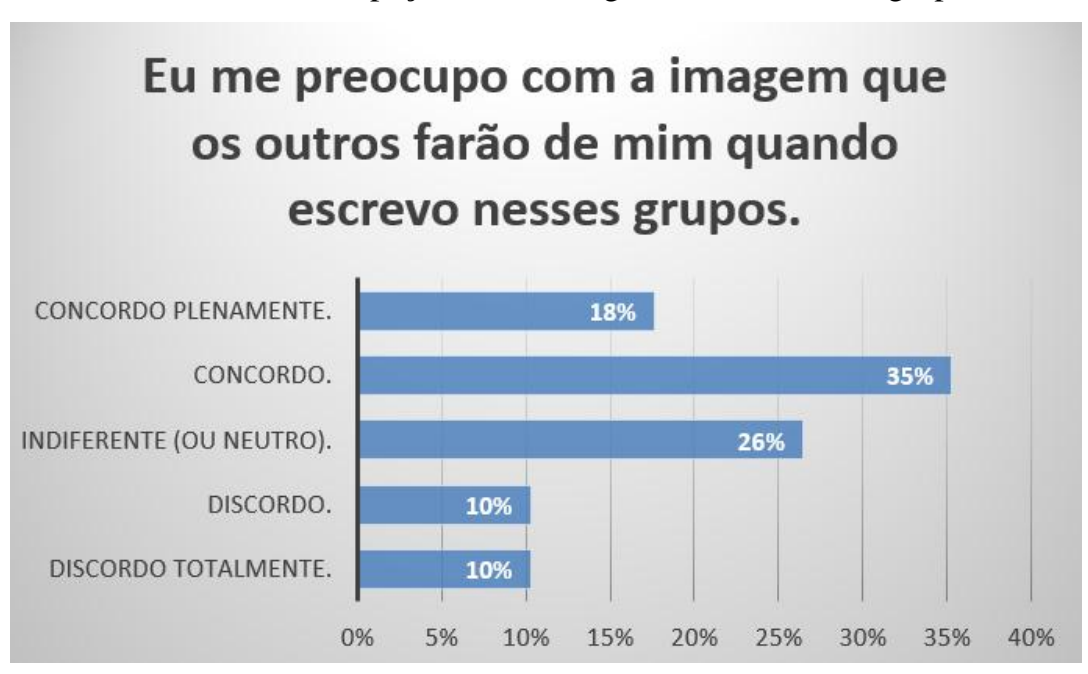

Fonte: Elaborado pelas Autoras (2019).

Quanto à utilização do corretor automático disponibilizado nos celulares, para diálogos no WhatsApp, o que foi evidenciado é que a maioria dos entrevistados (63\%) está com a ferramenta ativa em seus dispositivos. Ainda assim, é preciso ponderar que quase $35 \%$ (um percentual considerável) mantêm o recurso desativado, ou seja, por alguma razão não querem ou não se importam com os benefícios que pode trazer. Esse dado é bem relevante dentro do desenho da pesquisa, pois prova que mesmo entre os jovens estudantes, um público considerado no senso comum muito afeito às tecnologias móveis de comunicação e entretenimento, não é consensual o uso do corretor. 
Gráfico 5 - Utilização do corretor automático

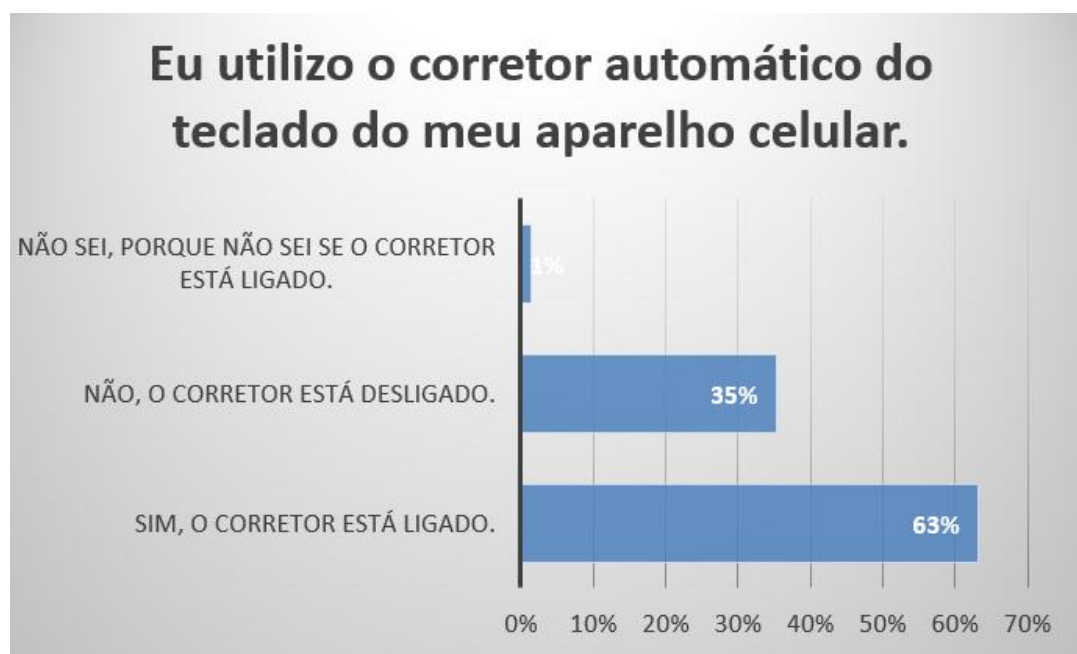

Fonte: Elaborado pelas Autoras (2019).

Mesmo havendo uso do corretor, o recurso específico da substituição automática de palavras não tem sido escolhido por mais da metade da amostra: 53\% estão com essa funcionalidade desativada, demonstrando desinteresse ou desagrado. Esse percentual revela que há participantes utilizando exclusivamente o recurso da correção por grifo e subsequentemente a sugestão do termo correto ou previsto, sem o recurso da substituição involuntária, que gera maior interferência no processo de escrita.

Ao serem indagados sobre a possibilidade de fixação de regras da norma culta com auxílio do corretor automático, 49\% disseram concordar, enquanto o restante não possui opinião definida a respeito ou discorda. Esse resultado evidencia que, independentemente do uso e da eficácia concreta na produção de mensagens escritas, os voluntários não estão plenamente certos da influência do corretor no fortalecimento do conhecimento gramatical formal - até porque, para tanto, teriam de ter por si só percebido qualquer possível facilidade e melhoria em seu desempenho, comportamento dificilmente observado nas práticas de uso do aplicativo. 
Gráfico 6 - Fixação de regras de escrita

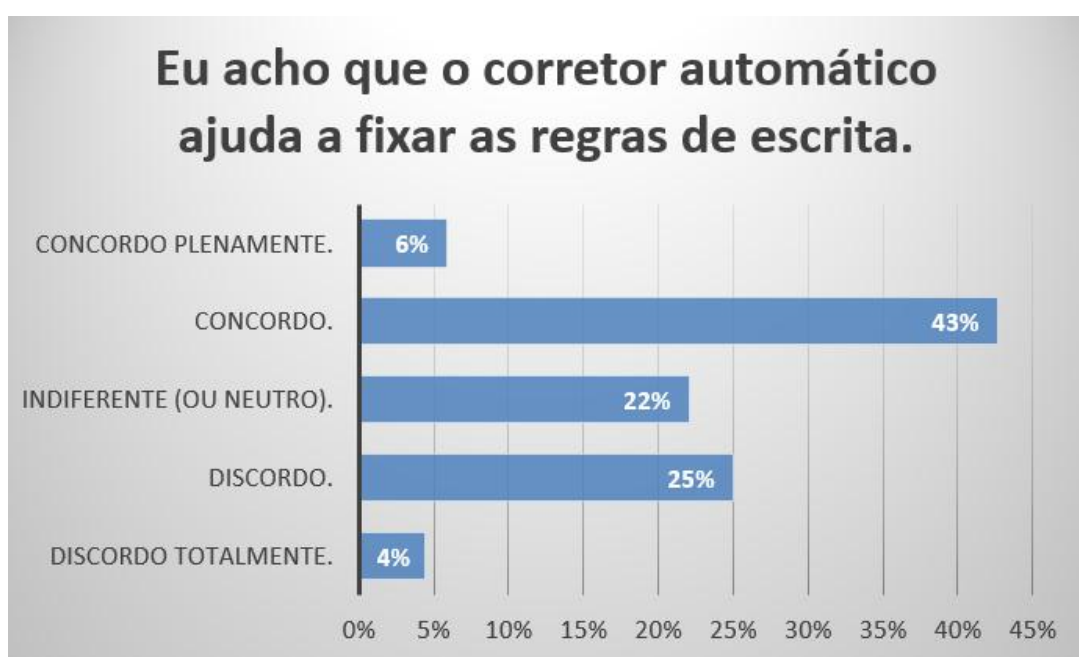

Fonte: Elaborado pelas Autoras (2019).

$\mathrm{Na}$ última questão, da mesma forma, os respondentes hesitaram em apostar de modo assertivo nas contribuições que o corretor pode trazer à aprendizagem do PB. $31 \%$ estão de acordo sobre o auxílio no desenvolvimento da variante prestigiada da língua escrita, mas um número maior de respondentes $(41 \%)$ discorda desse fato ou se mostra novamente indeciso (28\%), sendo possível inferir que quase $70 \%$ não confiam no potencial do WhatsApp para tal aprendizado.

Gráfico 7 - Aprendizado da língua portuguesa

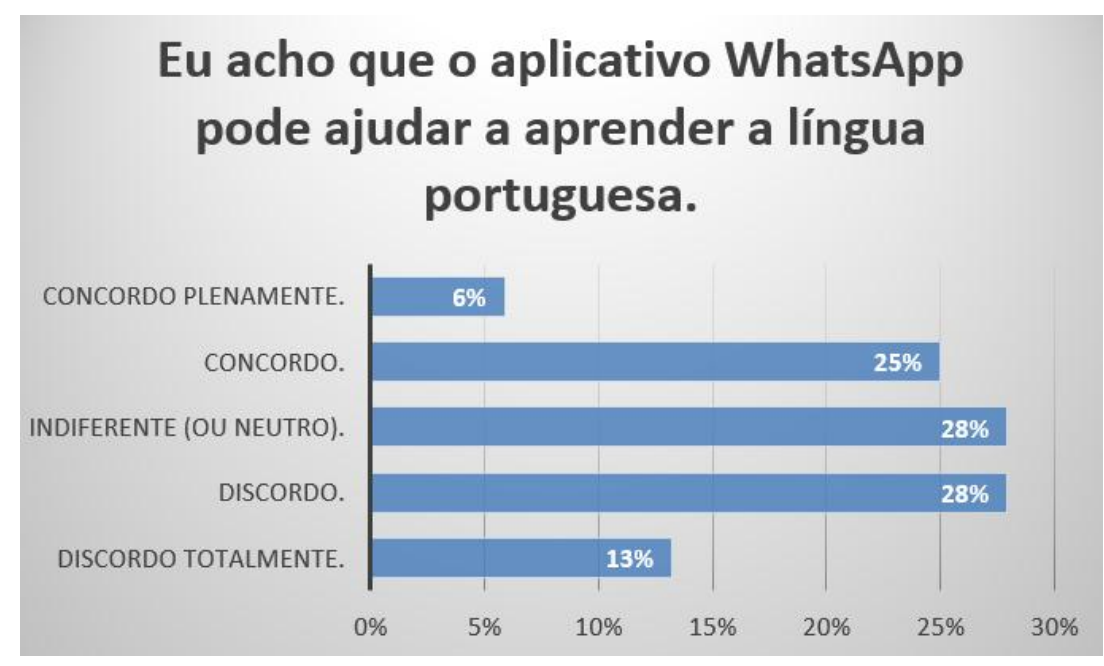

Fonte: Elaborado pelas Autoras (2019).

Pela observação do total de resultados obtidos, conclui-se que os usuários demonstraram, de modo geral, não vislumbrarem ou não possuírem confiança na 
potencialidade do corretor vinculado ao aplicativo WhatsApp para o aprimoramento de saberes da escrita em variante culta.

\subsection{ANÁLISE DOS RESULTADOS DA CONVERSAÇÃO SEM E COM WHATSAPP}

$\mathrm{Na}$ produção textual de conversação sem uso do WhatsApp, foram observadas inadequações na ortografia de regularidades diretas, contextuais ou morfológico-gramaticais, e irregularidades; bem como nos outros aspectos gramaticais contemplados no TCG. Os textos manuscritos eram pouco extensos, com uma média de 10 linhas, e de conteúdo raso, pouco aprofundado, nos quais estavam presentes erros também apontados na literatura recenseada, o que coaduna para reforçar a constatação de um frágil domínio de aspectos estruturantes da norma culta escrita.

No Gráfico 8, os desvios aparecem categorizados para elucidar as principais carências por parte dos 18 jovens estudantes do grupo de controle.

Gráfico 8 - Desvios na conversação sem WhatsApp

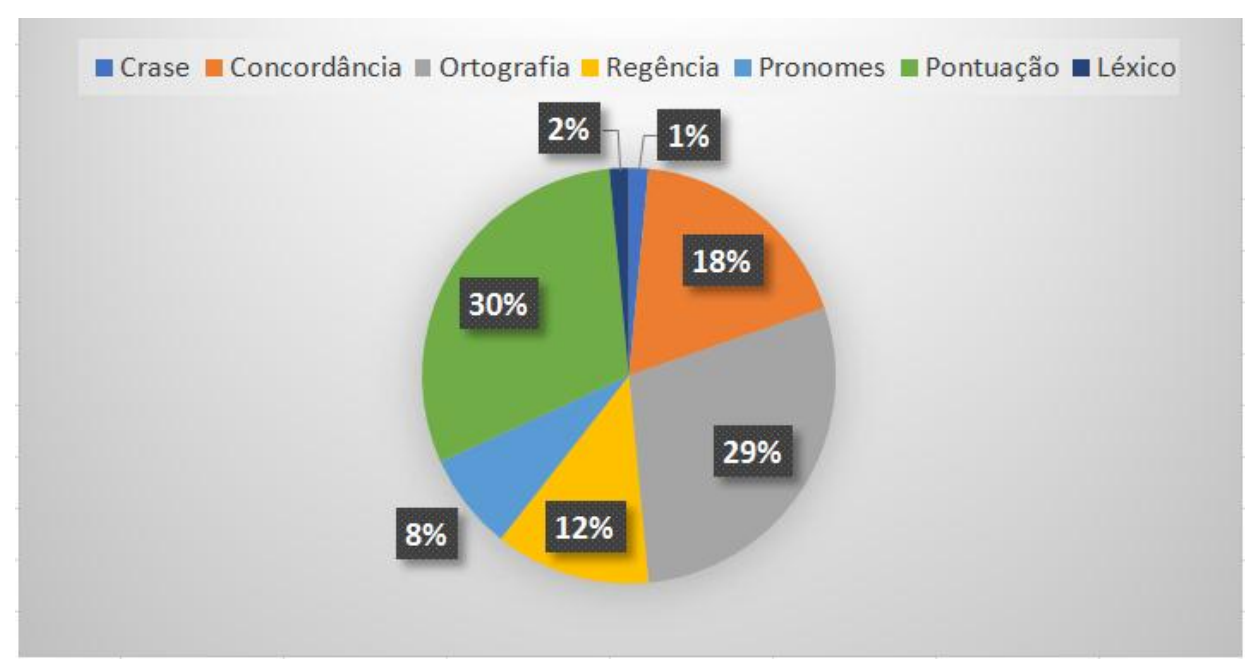

Fonte: Elaborado pelas Autoras (2019).

No chat via WhatsApp (Gráfico 9), não foi possível perceber ocorrências tão frequentes dos desvios de ortografia, colocação pronominal e pontuação observados no grupo anterior. O primeiro aspecto caiu de $29 \%$ para $4 \%$; o segundo, de $8 \%$ para $4 \%$; e o terceiro, de $30 \%$ para $11 \%$. Esses dados permitem afirmar que, na comparação, o grupo experimental comete menos desvios enquanto usam o corretor automático durante a interação. Entretanto, não é possível afirmar que, por esse motivo e nesse ensejo, os participantes tenham aprendido ou fixado o padrão gramaticalmente aceito graças ao recurso do aplicativo. 
Já em relação aos outros quatro aspectos investigados - léxico, crase, concordância e regência, as porcentagens subiram, indicando que o grupo experimental, bem mais numeroso (46 integrantes), desviou-se também mais das normas gramaticais referentes a eles, especialmente se for considerado que a extensão das mensagens digitadas, muitas vezes, era menor que a dos textos manuscritos.

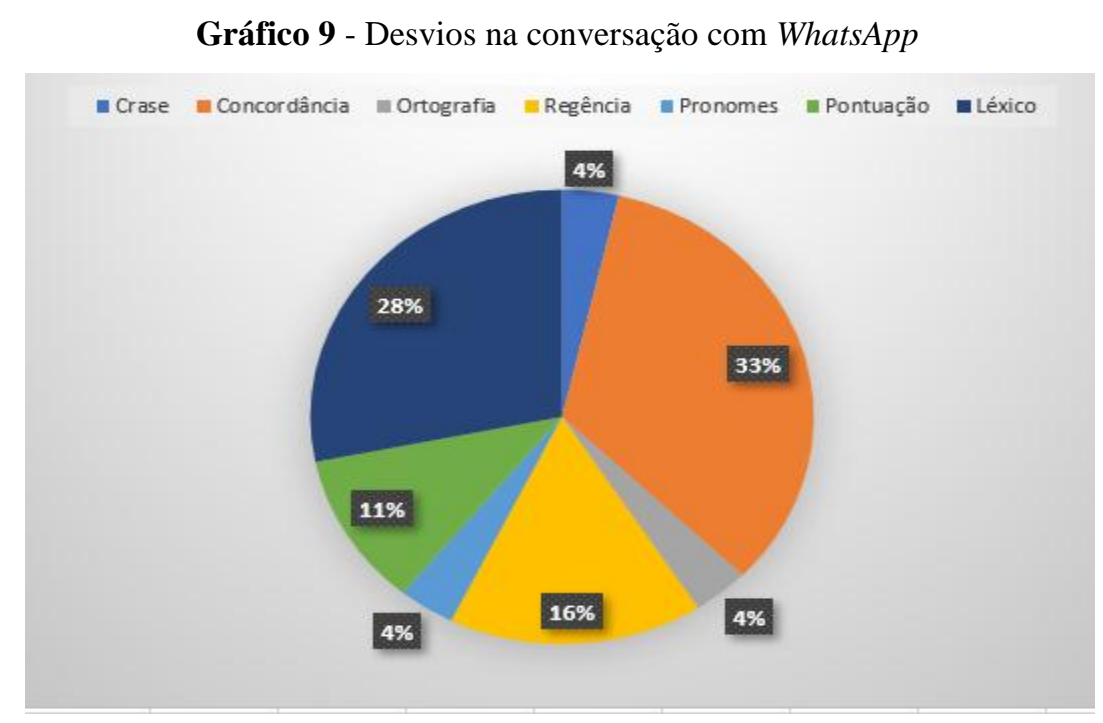

Fonte: Elaborado pelas Autoras (2019).

Os dois aspectos gramaticais que mais se alteraram foram léxico e concordância. Verificou-se igualmente que houve ocorrências de erros de digitação, com elipse de termos, como em "eu gostaria de começado" e "ajudar melhorar"; erros de acentuação em "area" e "à isso"; erros de ortografia em "fatec" (nome da instituição com inicial minúscula). Esses resultados levam a considerar que há semelhanças em certos desvios da norma padrão entre meios analógicos e digitais, porém resultam em produções linguísticas distintas devido a seus recursos próprios. Isso porque, além das previstas abreviações, muito utilizadas na digitação de mensagens, como em "pq" e "to", vistos na Figura 1 e que contribuíram para avolumar o número de inadequações lexicais, houve uso de emojis para enfatizar sentimentos de satisfação, alegria ou entusiasmo, também ilustrados na mesma figura. 
Figura 1 - Amostras da conversação com WhatsApp

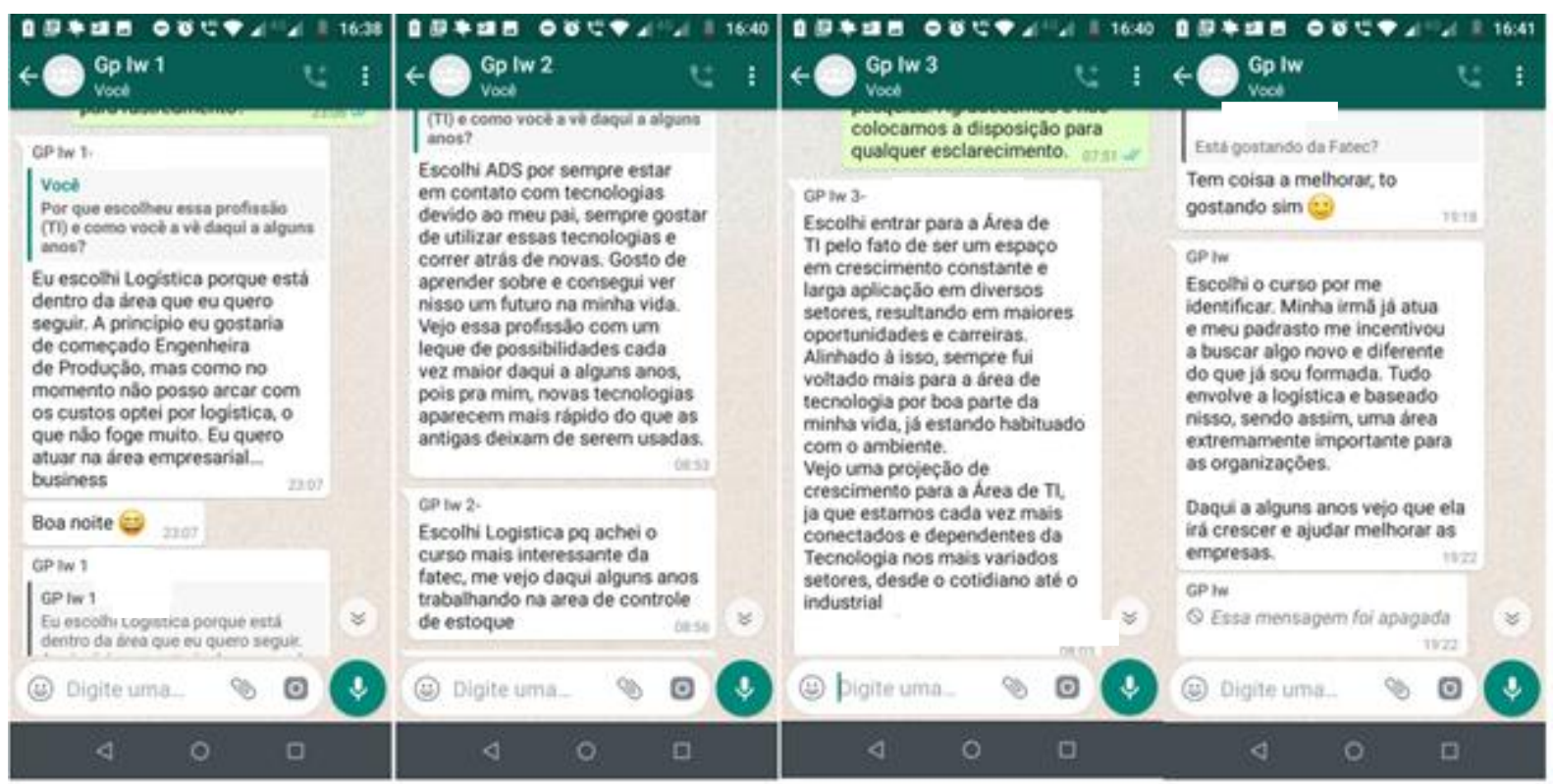

Fonte: Elaborado pelas Autoras (2019).

Fica evidente, assim, que o corretor, estando em uso nos 46 casos de indivíduos do grupo experimental, interveio na ocorrência de certos desvios da norma culta observados no grupo de controle, mas não foi suficiente para corrigir outros desvios, tais como os quatro já mencionados, e os de acentuação (restritos à crase no grupo de controle) e de abreviação (inexistentes no mesmo grupo).

\section{CONSIDERAÇÕES FINAIS}

Este estudo teve como objetivo principal averiguar o domínio da norma culta em PB por parte de jovens estudantes dos Ensinos Médio e Superior e o seu uso e a sua percepção do corretor automático vinculado ao WhatsApp, com a finalidade de observar possíveis interferências entre um e outro. A suposição era a de que esses jovens utilizassem diariamente o aplicativo em suas trocas comunicativas e que fizessem, com esse fim, uso massivo das funcionalidades do sistema, com a preocupação de demonstrar domínio da norma culta para se reconhecerem e serem reconhecidos "publicamente", no ciberespaço, como produtores competentes, o que faria desse algoritmo um meio de inclusão social.

Evidenciou-se nos dados observados que os estudantes concluem o Ensino Médio e ingressam no Ensino Superior com uma escrita com desvios generalizados da norma culta, em diversos aspectos gramaticais, com destaque à regência e concordância nominal e verbal. Além disso, como previsto, a maior tendência assinalada é do uso generalizado do aplicativo nas práticas comunicativas da amostra de indivíduos, possivelmente porque encontram nele o 
dinamismo desejado, ou até uma interessante alternativa às conversas telefônicas necessariamente faladas, à necessidade de respostas imediatas da comunicação face-a-face, a possíveis deficiências auditivas, à restrição de fala em certos contextos, como reunião, aula, consulta médica, e outros.

Evidenciou-se também, em contrapartida, certas cisões no grupo total de participantes em relação ao aplicativo estudado e seus recursos. Nem todos eles admitem que o domínio da norma culta seja necessário quando conversam por aplicativo e estão, no caso dos grupos de conversa, em evidência, sendo observados e julgados por terceiros. Nem todos são afeitos a esses grupos de WhatsApp, tampouco confiam nos recursos disponíveis ou visualizam os impactos que poderiam causar na aprendizagem linguística, contrariando a expectativa das pesquisadoras.

É notório que a apropriação da norma culta é um desafio, uma vez que "a compreensão de uma norma padrão passa pela percepção das dezenas ou centenas de linguagens que se estratificam na escrita cotidiana (...). As variedades são relevantes para o domínio do padrão - já que o próprio padrão não existe em si” (TEZZA, 2002, p. 42). Nesse sentido, outra suposição inicial era de que os jovens pesquisados demonstrariam preocupação de serem mais bem compreendidos em ambiente virtual através do domínio do padrão mais formal. O Teste de Correção Gramatical, o questionário que sondava a percepção dos participantes sobre seu desempenho e as potencialidades dos recursos que têm em mãos, e as produções textuais com e sem WhatsApp foram todos instrumentos para analisar esse domínio, e consequentemente refletir sobre a influência do corretor automático na aprendizagem desse padrão.

Foi possível realmente perceber que alguns desvios foram menos frequentes na escrita através do WhatsApp com corretor automático ativado do que fora dele, enquanto outros aspectos somados àqueles próprios da escrita digitada, como abreviações e emojis, sobressaíram. Tal constatação permite ponderar que deve ter sido por influência do corretor que os estudantes alcançaram tal desempenho, ou, ao menos, por influência do meio digital e da forma como estavam expostos uns aos outros no grupo de conversa; mas não permite mensurar exatamente o quanto o recurso interferiu (uma das limitações desta pesquisa), sendo que podem ter contribuído fatores também externos, como maior ou menor conhecimento prévio das regras pelo grupo experimental do que pelo de controle. Com efeito, porcentagens significativas dos jovens voluntários admitiram não estarem preocupados com a norma culta em PB quando redigem pelo aplicativo, talvez porque busquem com seu uso outras 
performances comunicativas que não essa. Parte deles, inclusive, demonstrou sequer utilizar os recursos existentes para aprimorar a escrita.

Esta pesquisa teve o intuito de contribuir com o debate recente sobre o papel das interações digitais envolvendo alunos e professores, ou grupos de adolescentes e jovens, com suas tantas expectativas profissionais (por isso foi solicitado que os voluntários se pronunciassem a respeito delas). Foi traçado aqui um panorama do conhecimento gramatical de uma amostra de alunos, do seu comportamento no manuseio do aplicativo em questão e da visão que têm desse aplicativo como influenciador gramatical, num panorama sociolinguístico de eminente inserção no mercado de trabalho.

Buscando atender a um público que tem expectativa de poder fazer uso de suas funcionalidades em sua formação escolar e profissional, os algoritmos de correção de texto usados em processadores de linguagem natural precisam que novos estudos sejam sempre feitos para que novas implementações possam ser realizadas. Uma pesquisa de caráter longitudinal, com uso de instrumentos estatísticos sofisticados, poderia ser desenvolvida nas instituições aqui escolhidas a fim de ampliar o escopo e aprofundar as análises, permitindo delimitar fases pré e pós-testes para atestar o quanto o corretor influencia a aprendizagem das normas em si.

\section{REFERÊNCIAS}

ALENCAR, L. F. Técnicas em software livre para exploração de corpora do português livremente disponíveis na WWW. Veredas On-Line, Juiz de Fora, v. 2, p.134-150, 2009. Disponível em: https://www.ufjf.br/revistaveredas/files/2009/11/ARTIGO-LeonelFigueiredo-de-Alencar.pdf . Acesso em: 28 abr. 2019.

ARAÚJO, E. M. E.; DIAS, I. S. O domínio da norma culta da língua portuguesa como determinante de inclusão/exclusão no mundo do trabalho. Revista Políticas Públicas, São Luís, v. 18, n. 1, p. 255-268, jan./jun. 2014. Disponível em: http://www.periodicoseletronicos.ufma.br/index.php/rppublica/article/download/2760/3895 Acesso em: 15 maio 2019.

BAGNO, M. Nada na língua é por acaso: ciência e senso comum na educação em língua materna. Revista Presença Pedagógica, 2006. Disponível em: http://relin.letras.ufmg.br/shlee/Bagno_2006.pdf. Acesso em: 5 maio 2019.

BOUHNIK, D.; DESHEN, M. WhatsApp goes to school: mobile instant messaging between teachers and students. Journal of Information Technology Education, v. 13, p. 217-231, 2014. Disponível em: http://www.jite.org/documents/Vol13/JITEv13ResearchP217231Bouhnik0601.pdf. Acesso em: 28 abr. 2019. 
CHURCH, K.; OLIVEIRA, R. What's up with whatsapp? Comparing mobile instant messaging behaviors with traditional SMS. Mobile HCI, Munich, p. 352-361, 2013. Disponível em: https://www.ic.unicamp.br/ oliveira/doc/MHCI2013_Whats-up-withwhatsapp.pdf. Acesso em: 20 nov. 2018.

ECO, U. Apocalípticos e integrados. São Paulo: Perspectiva, 2015.

GRÉGIS, R. A. Testes de julgamento gramatical em pesquisas de aquisição de segunda língua. 2007. 240 f. Tese (Doutorado em Letras) - Pontifícia Universidade Católica do Rio Grande do Sul, Porto Alegre, 2007.

LANIER, J. Dez argumentos para você deletar agora sua redes sociais. Rio de Janeiro: Intrínseca, 2018.

LUCCHESI, D. Introdução. In: LUCCHESI, D.; BAXTER, A.; RIBEIRO, I. (org.). O português afro-brasileiro. Salvador: EDUFBA, 2009, p. 27-37. Disponível em: http://books.scielo.org/id/p5/pdf/lucchesi-9788523208752-03.pdf. Acesso em: 28 abr. 2019.

MANJOO, F. How your cell phone's autocorrect software works, and why it's getting better. Slate, [S. l.], 2010. Disponível em: https://slate.com/technology/2010/07/how-your-cellphone-s-autocorrect-software-works-and-why-it-s-getting-better.html. Acesso em: 11 maio 2019.

MCLUHAN, M. Os meios de comunicação como extensões do homem. São Paulo: Cultrix, 1964.

NUMBER of Facebook users in Brazil from 2017 to 2023. Statista.com, New York, 2019. Disponível em: https://www.statista.com/statistics/244936/number-of-facebook-users-inbrazil/. Acesso em: 13 out. 2019.

NUNES, M. G. V.; OLIVEIRA JR, O. N. O processo de desenvolvimento do revisor gramatical ReGra. Núcleo Interinstitucional de Lingüística Computacional, São Carlos, SP, 2000. Disponível em:

http://www.niee.ufrgs.br/eventos/SBC/2000/pdf/semish/semi001.pdf. Acesso em: 12 ago. 2019.

PEREIRA, S. L. Processamento de linguagem natural. São Paulo: USP, 2011. Disponível em: https://www.ime.usp.br/ slago/IA-pln.pdf. Acesso em: 28 abr. 2019.

PITTOL, E.; RIGO, S. J. Certografia: um corretor ortográfico automático para português e resultados de um estudo de caso aplicado na área jurídica. Revista Brasileira de Computação Aplicada, Passo Fundo, v. 7, n. 3, p. 31-42, out. 2015. Disponível em: http://seer.upf.br/index.php/rbca/article/view/3776/3508. Acesso em: 25 jul. 2018.

RAMBE, P; CHIPUNZA, C. Using mobile devices to leverage student access to collaboratively-generated resources: a case of whatsapp instant messaging at a South African University. INTERNATIONAL CONFERENCE ON ADVANCED INFORMATION AND COMMUNICATION TECHNOLOGY FOR EDUCATION., Hainan, China. [Proceedings...]. Hainan, China: Atlantis Press, 2013. Disponível em: https://www.researchgate.net/publication/266645202_Using mobile_devices to leverage_stu 
dent_access_to_collaboratively-

generated_resources_A case_of_WhatsApp_instant_messaging_at_a_South_African_Univer sity. Acesso em: 29 nov. 2019.

RIEMENS, N. De directe invloed van whatsapp op schrijfvaardigheid. BA thesis, Radboud University, 2016.

SABE como funciona o corretor ortográfico do seu smartphone? Agência Trato, Rio de Janeiro, 27 dez. 2018. Disponível em: http://agenciatrato.com.br/blog/sabe-como-funciona-ocorretor-ortografico-do-seu-smartphone/. Acesso em: 13 dez. 2019.

SERRES, M. O contrato natural. Lisboa: Instituto Piaget, 1994.

SINGH, A. Facebook, WhatsApp, and Twitter: Journey towardsEducation. SOSHUM, v. 8, n.2, 2018. Disponível em: ojs.pnb.ac.id/index.php/SOSHUM/article/download/987/799/. Acesso em: 28 abr. 2019.

SOUZA, J. M.; QUIRINO, M. P. C. Reflexões sobre tecnologias móveis: construindo um ambiente de aprendizagem centrado na "geração polegar". Revista Saberes, ano 2, n. 2, v. 1, p.90-102, jan./abr. 2015. Disponível em: https://www.faculdadeages.com.br/uniages/revistasaberes-no-2-faca-o-download/. Acesso em: 28 abr. 2019.

TEZZA, C. Material didático - um depoimento. Educar, Curitiba, n. 20, p. 35-42, 2002. Disponível em:

https://www.scielo.br/j/er/a/B4J8wqGbFsHSqCf3qkF7TSG/?lang=pt\&format=pdf . Acesso em 29 nov. 2019.

UEBERWASSER, S.; STARK, E. What's up, Switzerland? A corpus-based research project in a multilingual country. Linguistik Online, v. 84, n. 5, p.105-126, 2017. Disponível em: https://bop.unibe.ch/linguistik-online/article/view/3849/5833. Acesso em: 10 ago. 2019.

VERHEIJEN, L.; SPOOREN, W. The impact of whatsapp on dutch youths' school writing. CONFERENCE ON CMC AND SOCIAL MEDIA CORPORA FOR THE HUMANITIES, 5., Italy. [Proceedings...]. Bolzano, Italy: Eurac Research, 2017. P. 6-10. Disponível em: https://repository.ubn.ru.nl/bitstream/handle/2066/177272/177272.pdf. Acesso em: 10 jul. 2019.

VITÓRIA, M. I. C.; CHRISTOFOLI, M. C. P. A escrita no ensino superior. Educação Santa Maria, v. 38, n. 1, p. 41-54, jan./abr. 2013. Disponível em:

http://repositorio.pucrs.br/dspace/bitstream/10923/8741/2/A_escrita_no_Ensino_Superior.pdf. Acesso em 29 nov. 2019.

WEISSHEIMER, J.; CALDAS, V.; MARQUES,F. Using Whatsapp to develop L2 oral production. Revista Leitura, v. 1, nº 60, Maceió, p. 21-38, Jan./Jun. 2018. Disponível em: https://www.seer.ufal.br/index.php/revistaleitura/article/view/4208. Acesso em 28 abr. 2019. 